\title{
Kahoot e a linguagem gamificada: uma tática docente do uso dos multiletramentos
}

\author{
Valtemir dos Santos Rodrigues ${ }^{1}$, Andrea Cristina Versuti ${ }^{2}$, CláudiaVieira Barboza \\ Sumikawa ${ }^{3}$
}

\begin{abstract}
RESUMO
Neste artigo apresentamos resultados dos usos do dispositivo Kahoot em diferentes atividades pedagógicas realizadas com os alunos da educação básica da rede pública de ensino do Distrito Federal (DF). Os resultados advêm do recorte de duas pesquisas de mestrado, de cunho qualitativo, que investigaram um curso de formação continuada de professores emmetodologia da transmidiação inédito no Brasil. O curso criado pelo Centro de Referência em Tecnologia Educacional (CRTE) da Região Administrativa de Taguatinga (DF) e aplicado em 2019 visando aproximar os docentes do uso pedagógico de dispositivos digitais. Nas pesquisas,foram usados como instrumentos para construção de dados: a observação não participante, a aplicação de questionários e entrevista semiestruturada.Como resultado, o Kahoot no curso: 1) promoveu o engajamento dos estudantes; 2) reforçou o trabalho cooperativo; 3) ajudou a enriquecer e fixar conteúdos curriculares e 4) ajudou a tornar o processo de ensino interativo e dinâmico. Além disso, enalteceu a importância da formação docente continuada para o uso pedagógico das linguagens e alertou para a necessidade de investimento em infraestrutura tecnológica nas escolas.
\end{abstract}

Palavras-chave: Kahoot; Transmidiação; Formação Continuada Docente; Gamificação; Multiletramentos; Dispositivos Digitais

\begin{abstract}
In this paper, we present the results of the uses of the Kahoot device in different pedagogical activities carried out with basic education students from the public school system in the Federal District (DF). The results come from the clipping of two master's researches, of a qualitative nature, which investigated a continuing education course for teachers in the methodology of transmediation, unprecedented in Brazil. The course created by the Educational Technology Reference Center (ETRC) of the Administrative Region of Taguatinga (DF) and applied in 2019 to bring teachers closer to the pedagogical use of digital devices. In the surveys, the following instruments were used for data construction: non-participant observation, the application of questionnaires and semi-structured interviews. As a result, Kahoot in the course: 1) promoted student engagement; 2) reinforced cooperative work; 3 ) it helped to enrich and fix curricular contents and 4) it helped to make the teaching process interactive and dynamic. In addition, he highlighted the importance of continuing teacher education for the pedagogical use of languages and warned of the need for investment in technological infrastructure in schools.
\end{abstract}

\footnotetext{
1 Universidade de Brasília. E-mail: valtemir.rodrigues@gmail.com

2 Universidade de Brasília. E-mail: claudiavieirabarboza@gmail.com

3 Universidade de Brasília. E-mail: andrea.versuti@gmail.com
} 
Keywords: Kahoot; Transmediation; Continuing Teacher Training; Gamification; Multiliteracies; Digital Devices

\section{INTRODUÇÃO}

O perfil do alunado nas escolas tem sofrido uma mudança significativa nos últimos tempos, especialmente pelos avanços das Tecnologias Digitais da Informação e da Comunicação (TDIC), muito presente na vida desses jovens. As crianças e os adolescentes nascidos e criados na era tecnológica apresentam novos modos de aprender, o que implica em demandas diferenciadas e aos docentes, criados em outro contexto social, e que agora se veem no dever de buscar táticas para atender a essas demandas.

Esses jovens estão conectados em rede, possuem acesso facilitado às informações, são produtores de conteúdo (vídeos, textos, músicas, charges, memes), jogam em ambiente on-line. Dados da pesquisa TIC Kids Online de 2018 do Comitê Gestor da internet no Brasil (CGI) e divulgados em novembro de 2019 dimensionam isso. Segundo os números, dos estudantes de 9 a 17 anos, $86 \%$ eram usuários deinternet; 83\% reportaram ter assistido vídeos, programas, filmes e séries on-line; $83 \%$ possuíam perfis em redes sociais; $77 \%$ enviaram mensagens instantâneas; $82 \%$ escutaram música on-line; $60 \%$ jogaram na internet sem conexão com outros jogadorese $55 \%$ jogaram conectados com outros jogadores.

Outros dados do mesmo instituto de pesquisa, de 2017, também mostraram que o ambiente on-line não é usado pelos jovens apenas para o lazer. Os números do CGI revelaram que a web é utilizada por $80 \%$ dos estudantes para produzir trabalhos escolares; $65 \%$ para fazer exercícios e lições que o professor passa; $86 \%$ para realizar pesquisas escolares; $56 \%$ para jogos educativos; $26 \%$ para falar com o professor; $73 \%$ para produzir trabalhos em grupo e $72 \%$ para estudar para provas. E se considerarmos o contexto da pandemia ocasionada pelo coronavírus em 2020, a chance desses números terem crescido é maior.

De acordo com Serres (2013), trata-se da população Polegarzinha, ou seja,aqueles que nasceram no fim do século XX e que estão em contato com o mundo virtualdesde o seu nascimento. Para o autor, essa população Polegarzinha vive, pensa, escrevee se 
comunica de outra forma, distinta daquela praticada pelos adultos. Com poucos cliques, ela tem acesso às informações que quiser, não dependendo apenas de escolas, bibliotecas ou livros. "Se tiver consultado um bom site na internet, a Polegarzinha pode saber tanto ou mais sobre o assunto tratado que um professor, jornalista, um responsável, um chefão, um eleito ou até um presidente" (SERRES, 2013, p. 76).

Para lidar com essa população jovem e atingir os objetivos de ensinoaprendizagem partimos do pressuposto de que uma possibilidade é que o professor não se restrinja ao modo tradicional de ensinar, mas que traga novos elementos e seja mediador de um processo educacional baseado no trabalho colaborativo e na utilização de narrativas que sejam interessantes aos estudantes, representem seus gostos e possam funcionar como dispositivo de transformação pessoal e social. Entendemos que a rede mundial de computadores e o território da cibercultura tem se mostrado um caminho para isso, principalmente, no que diz respeito a sua utilização.

Além disso, acreditamos que a presença das tecnologias nas escolas pode contribuir para a melhoria nos processos formativos, mas por si só não é efetiva.Partimos da premissa de que elas trazem inovações e abrem caminhos para mudanças, que dependerão da sua utilização. Portanto, caberá ao professor utilizar as TDIC, não apenas para reproduzir o ensino tradicional, mas para incorporar a ele outros processos de aprendizagem. Isso viabiliza abrir caminhos para a superação da hierarquia e submissão de inteligência, desmistificar a figura do professor como centralizador do conhecimento, além de instigar a criação, a invenção e o pensamento crítico.

Frente a esse cenário desafiador e em constante mudança, um curso de formação continuada para docente inédito no país foi proposto pelo Centro de Referência em Tecnologia Educacional de Taguatinga (CRTE), em 2018, e implementado no início de 2019, com a finalidade de familiarizar os professores da Secretaria de Educação do Distrito Federal (SEE/DF) com as linguagens digitais e investigar suas potencialidades para o campo educacional. A formação continuada intitulada Uso de Ferramentas Digitais para Otimização do Processo de Aprendizagem (UFDOPA) teve como foco a criação e a elaboração de textos narrativos transmidiáticos por meio dos dispositivos digitais Bitmoji, Toondoo, Kahoot, Openshot, Boomerang e Google Apresentações.

O curso, foi criado para a formação de professores da rede pública de ensino do Distrito Federal dos diversos componentes curriculares e níveis de ensino, pensado a 
partir da apropriação teórica com aplicabilidades práticas da metodologia da transmidiação. Seu conceito é entendido como a possibilidade de trazer outras escritas, motivadas por outros desejos, por configurações de pensamento que rompem o "perigo de uma estória única" propondo assim o exercício de imaginar, criar outros desfechos e desdobramentos para obras canonizadas, conhecidas e repetidas.

A partir desse horizonte, a formação continuada docente trouxe também em sua composição conceitos de multiletramentos, trabalhando dessa forma com vários dispositivos, entendidos como "qualquer coisa que tenha de algum modo a capacidade de capturar, orientar, determinar, interceptar, modelar, controlar e assegurar os gestos, as condutas, as opiniões e os discursos dos seres viventes." (AGAMBEN, 2015, p. 39).

Portanto, a partir dessa formação docente nasceram duas pesquisas acadêmicas no interior do programa de Pós-Graduação em Educação da Universidade de Brasília (PPGE/UnB), mais especificamente na linha de pesquisa Educação, Comunicação e Tecnologias (ETEC). A primeira delas teve como propósito analisar a formação continuada de professores para os multiletramentos e suas contribuições na aplicação e no desenvolvimento de metodologia da transmidiação de conteúdos, e a segunda investigação se propôs a identificar quais as repercussões uma formação docente em metodologia da transmidiação podem promover nas práticas pedagógicas em sala de aula. Como resultado, comprovou-se que a formação docente gerou aulas diferenciadas, estimulou o engajamento dos estudantes e demonstrou que professores mais alinhados às necessidades dos alunos geram resultados melhores.

Pensamos os exercícios de transmidiação como ato de tradução de um sistema sígnico para outro que amplia as oportunidades de desenvolvimento para um pensamento gerador/gerativo e reflexivo, construindo conexões entreas diferentes linguagens e a criação de novas formas alternativas ao verbocentrismo praticado na educação formal, ou seja, compreendemos este esforço como prática de tradução intersemiótica para a transposição de conteúdos entre sistemas sígnicos distintos (VERSUTI; SILVA, 2017, p. 95).

Durante o curso, os professores eram orientados a fazer experimentações com cada dispositivo explorado e ao final tinham que apresentar uma proposta pedagógica que 
tivesse sido aplicada em sala e que contemplasse um ou mais dispositivos trabalhados durante o curso. No decorrer da formação, onze experimentações foram feitas com o dispositivo Kahoot e quatro projetos finais o contemplou. Além disso, nas observações não participantes ocorridas durante a formação docente e nas experimentações em sala de aula o dispositivo se mostrou mais atrativo aos estudantes, principalmente pela linguagem da gamificação que, segundo Fardo (2013, p. 3), encontra na educação formal uma área bastante fértil para a sua aplicação, pois nestes contextos ela encontra os indivíduos que carregam consigo muitas aprendizagens vindas de interações com os games.

Dessa forma, fizemos um recorte nos estudos feitos e trouxemos para este artigo a seguinte questão norteadora: como o uso do Kahoot e da linguagem gamificada pode ser usada como uma tática docente do uso dos multiletramentos? Para essa contextualização, utilizamos como metodologia a observação não participante no curso de formação docente e aplicação de exercícios com o dispositivo em uma turmade $5^{\circ}$ ano do ensino fundamental I, escolhida em razão da proposta didática apresentada pela professora cursista durante a formação docente. Além disso, foram analisadas as propostas pedagógicas apresentadas no curso com o uso do Kahoot, a entrevista com a professora da turma escolhida e os relatos escritos acerca do trabalho com os dispositivos feitos pelos estudantes à professora como parte da atividade executada.

Para a análise dos relatos dos estudantes nos valemos do software Iramuteq, que permite fazer a análise textual, extraindo dali os principais núcleos de sentido. Nos valemos de dois recursos: o gráfico de similitude e a nuvem de palavras, que nos apresentaram as conexões de sentido entre as palavras no corpus textual revelando os núcleos de significação e a agrupação dos termos mais relevantes (CAMARGO; JUSTO, 2013, p. 2).

Com o intuito de ampliar a discussão e compreender como a temática tem sido explorada em pesquisas acadêmicas, fizemos também uma Revisão Sistemática de Literatura (RSL) considerando as teses e as dissertações nacionais publicadas no período de 2015 a 2020 e disponibilizadas nas bases de dados da Biblioteca Digital de Teses e Dissertações (BDTD), no Banco de Teses e Dissertações da Capes e no Portalde Periódico Capes. Conforme explicam Medina e Pailaquelén (2010), essas revisões 
“sintetizam os resultados de múltiplas pesquisas primárias, usando estratégias parareduzir viés e erros de azar."

Para a melhor compreensão da temática, o artigo está dividido nas seguintes seções: introdução, fundamentação teórica, contextualização do curso em formação em docente continuada, apresentação do Kahoot enquanto dispositivo, revisão sistemática de literatura, análise ediscussão dos dados e, por fim, as considerações acerca dos resultados encontrados a partir das discussões. Com essa produção objetivamos elucidar uma das possibilidades oferecidas pela transmidiação e o trabalho pedagógico com os dispositivos digitais.

\section{FUNDAMENTAÇÃO TEÓRICA}

A convergência das mídias e o avanço tecnológico proporcionaram mudanças expressivas na sociedade, alterando diretamente a configuração dos processos de ensinoaprendizagem. Antes, os estudantes aprendiam na escola informações que apenas o seu professor detinha, mas hoje esse mesmo aprendizado pode ser obtido por diversas outras fontes. Com os conhecimentos à sua disposição nas redes virtuais e com o poder de carregá-los no bolso por meio de um telefone móvel com acesso à internet, por exemplo, a prática de ensino tradicional mostra-se insuficiente, sendo necessária a criação de táticas para que o novo e o antigo caminhem juntos.

Diante desse cenário, a educação formal é levada a repensar as maneiras para atrair os estudantes para o processo de construção do ensino e fazer com que a aula tradicional, pautada na oratória, giz e lousa agregue novos elementos, componentes ao processo de ensino e aprendizagem. Diante disso, o uso das tecnologias é visto como uma saída possível, principalmente pela contribuição que traz para uma nova relação ensinoaprendizagem para todos os estudantes.

A revolução tecnológica que vivemos não afeta apenas individualmente a cada um dos meios, mas produz transformações transversais que se evidenciam na emergência de 
um ecossistema educativo conformado não só por novas máquinas ou meios, mas por novas linguagens, escritas e saberes, pela hegemonia da experiência audiovisual sobre a tipográfica e a reintegração da imagem ao campo da produção de conhecimentos (BARBERO, 2014, p. 66).

Por meio dessa conectividade surgem novas maneiras de aprender e de ensinar, principalmente porque a aprendizagem e a construção do conhecimento estão pautadas na diversidade de opiniões e na realização de múltiplas tarefas, como ler, assistir, falar, interagir. Portanto, em meio à conexão de diferentes fontes de informação oportunizadas pela convergência digital, a capacidade de criação e de compartilhamentode ideias é muito favorecida e faz com que o aprendizado seja contínuo promovendo a formação de comunidades de aprendizagem.

Segundo Kenski (2012), a nova forma de ensinar deve ser vinculada às alterações do papel do professor e das escolas. Para ela, é necessário ampliar espaços e outras aprendizagens não escolares, oferecer ambientes, tempos, lugares diferenciados eensino ao estudante (presencial e a distância), a qualquer momento e onde ele estiver, além de envolver a todos na construção individual e coletiva dos conhecimentos.

Neste novo cenário, Moran (2007) diz que é preciso o educador mobilizar e assumir que "seu papel agora é o de gerenciador do processo de aprendizagem, o coordenador de todo o andamento, do ritmo adequado, o gestor das diferenças e das convergências." Em suas palavras, nessa conjuntura, "o presencial se virtualiza e a distância se presencializa. Os encontros em um mesmo espaço físico se combinam com os encontros virtuais, à distância, por meio da internet” (MORAN, 2007, p. 89).

Frente a esse cenário, acreditamos que a presença das tecnologias nas escolas pode contribuir para a melhoria nos processos formativos, mas por si só não é efetiva. Partimos da premissa de que elas trazem novos elementos para a sala de aula e abrem caminhos para mudanças que dependerão da sua utilização. Portanto, caberá ao professor utilizar as TDIC, não apenas para reproduzir o ensino tradicional, mas para incorporar a ele outros processos de aprendizagem. Isso viabiliza abrir caminhos para a superação da hierarquia e submissão de inteligência, desmistificar a figura do professor como centralizador do conhecimento, além de instigar a criação, a invenção e o pensamento crítico. 
Nesse contexto, a introdução da gamificação no ensino se apresenta como um caminho viável para práticas diferenciadas nas quais os estudantes são atraídos para o processo de aprendizagem. De acordo com Fardo (2013), o uso da gamificação na educação promove uma aprendizagem mais dinâmica, rápida e agradável.

Encontra na educação formal uma área bastante fértil para a sua aplicação, pois lá ela encontra os indivíduos que carregam consigo muitas aprendizagens advindas das interações com os games. Encontra também uma área que necessita de novas estratégias para dar conta de indivíduos que cada vez estão mais inseridos no contexto das mídias e das tecnologias digitais ese mostram desinteressados pelos métodos passivos de ensino e aprendizagem utilizados na maioria das escolas (FARDO, 2013, p. 3).

A gamificação é um recurso que promove o engajamento dos estudantes no processo de aprendizagem permitindo que se saia de um sistema no qual o professor é detentor do conhecimento e o aluno um agente passivo na sala de aula. Neste outro formato, onde o docente se torna um facilitador e o aluno um agente ativo no processo de aprendizagem. Além do engajamento, há vários outros benefícios, conforme enumera Marcandali (2020, p. 39):

1) Aprender de forma lúdica - os projetos de gamificação são elaborados para que a experiência seja divertida. Os usuários trocam pontos, ganham medalhas, escolhem cenários, criam avatares;

2) Conquistar habilidades e superar obstáculos - muitas gamificações são realizadas em etapas de progressão, a cada etapa o participante precisavencer desafios e superar obstáculos. É comum o aprendizado de novas habilidades estar presente nestes desafios;

3) Trabalhar em equipe, colaborar - As soluções permitem o trabalho em equipe, e/ou a colaboração com outros jogadores como doação de pontos, dar dicas das fases posteriores, postar comentários que agregam;

4) Adquirir novos hábitos - muitas soluções gamificadas têm como desafios a criação de novos hábitos como praticar algum esporte, incluir alimentos saudáveis no cardápio diário, diminuir a geração de resíduos. 
Mas para que benefícios ocorram de fato, entendemos que é preciso o professor estar preparado tendo sua profissão valorizada enquanto especificidade e atendida a necessidade de políticas públicas atuantes para promover a formação docentecontinuada de forma efetiva. É preciso que o professor tenha condições objetivas de se qualificar e conhecer estas novas linguagens. Nesse sentido, defendemos a formação docente direcionada para tal para que possam ter conhecimento sobre as possibilidades pedagógicas pelos dispositivos digitais, a exemplo da Gamificação, principalmente porque o domínio pedagógico das tecnologias na escola é complexo, demorado e muitos profissionais relutam em utilizá-las por não se sentirem preparados para lidar com elas.

Conforme defende Santos (2014), em tempos atuais é preciso investir em pedagogias que lancem mão das mídias, dos aplicativos e das soluções específicas como, por exemplo, os dispositivos digitais. "As tecnologias digitais em rede ampliam em potência nossa autoria, uma vez que ler e escrever são ações corriqueiras que fazemos com esses dispositivos" (SANTOS, 2014, p. 41).

A formação docente que apresentamos como uma possibilidade caminha nessa direção. Conforme detalhamos na sessão seguinte, ele oportuniza que o docente faça uma imersão nas experiências pedagógicas digitais e a partir daí possa pensar e inserir em suas escolas atividades pedagógicas diferenciadas e em consonância com a cibercultura.

\section{FORMAÇÃO DOCENTE PARA O USO DOS MULTILETRAMENTOS}

O curso UFDOPA teve como objetivo orientar professores na elaboração do planejamento de aulas com base na construção e expansão de novas narrativas alinhadas ao conteúdo curricular, com o auxílio de diferentes dispositivos da tecnologia digital. Para que os professores pudessem pensar a criação de narrativas em diferentes linguagens, a proposição do curso foi trabalhar com eles a produção de vídeos, histórias em quadrinhos, tirinhas, imagens, jogos, quiz e avatares por meio dos dispositivos Bitmoji, Toondoo, Kahoot e Openshot. Entendemos que as experiências e os usos com eles podem favorecer 
a aproximação dos professores com as novas linguagens e assim poder inseri-las em suas práticas pedagógicas de acordo com a necessidade.

O curso foi realizado nos CRTEs de Taguatinga, Samambaia, Planaltina, Paranoá e Sobradinho. Entretanto, para fins de pesquisa, foi escolhido o de Taguatinga após a observação do curso piloto, considerando o fato de esse último ter sido o local com maior número de cursistas, ter contemplado docentes de várias regiões administrativas do Distrito Federal e ter tido professores de todos os níveis de ensino. Ocurso piloto aconteceu entre os meses de abril e junho de 2019, e a segunda oferta reformulada ocorreu entre os meses de agosto a outubro de 2019.

A carga horária total do curso de formação docente foi de 90 horas, das quais 30 horas foram presenciais e 60 horas à distância. Foram dez encontros presenciais com atividades práticas realizadas no laboratório do CRTE, com a finalidade de contribuir para o conhecimento, exploração e apropriação das diferentes linguagens, tanto pormeio de aplicativos, dispositivos móveis quanto por programas de computador. Já o ambiente on-line foi utilizado o Google sala de aula para a disponibilização dos materiais de apoio, hospedagem dos trabalhos, fórum de discussões e publicação de atividades e avisos.

Em cada encontro presencial, o formador iniciava a aula com o feedback das atividades na modalidade de Educação a Distância (EAD) da aula anterior que foram disponibilizadas no Ambiente Virtual de Aprendizagem (AVA) e tecia comentários com o grupo a respeito das possibilidades de aplicação e exploração em sala de aula com seus alunos. Em seguida, apresentava e explorava com os cursistas, cada um no seu computador, o dispositivo a ser estudado no dia. $\mathrm{Na}$ aula seguinte, os professores continuavam com a exploração e sua produção autoral, vislumbrando as possibilidades de conexão com seus conteúdos curriculares de sala de aula. Entre uma aula presencial e a outra, os cursistas podiam explorar o aplicativo estudado no curso em uma atividade elaborada para ser realizada com seus alunos ajustando ao seu contexto profissional.

Ao final do curso, todos os participantes apresentaram para a turma seus projetos. Explicaram como aconteceu todo o processo de aplicação, desenvolvimento e repercussão do uso dos dispositivos em sala na construção de novas narrativas. Também enviaram para o AVA a Matriz de Design Educacional (MDE) devidamente preenchida, com os dados do planejamento do projeto e/ou da aula aplicada em suas escolas. A ideia 
é de que pudessem explorar as linguagens usando os dispositivos, adaptando as propostas realizadas no curso às condições da sua escola.

Das proposições feitas como projeto final da formação docente, quatro exploraram o Kahoot, que é o objeto de nossa análise aqui neste texto. Das abordagens analisadas, encontramos: revisão de conteúdo para provas, avaliação prévia de conhecimento e sondagem da aprendizagem de determinado conteúdo ministrado. Alémdisso, durante o curso, após serem familiarizados para o uso do dispositivo, 11 experimentações foram feitas e uma foi escolhida para ser acompanhada de perto. Foi uma turma de $5^{\circ}$ ano da Escola Classe 42 de Taguatinga, composta por 27 estudantes, e cuja atividade foi a revisão de conteúdos para a prova de Ciências.

Para a execução da dinâmica, a professora solicitou aos estudantes que fizessem o estudo prévio do conteúdo, recomendou aos alunos que possuíam smartphone a leválos para a sala de aula e montou uma estrutura com notebook e projetor. No dia da atividade, os alunos foram divididos em grupos mistos e a professora atuou como mediadora, indicando o tempo para as respostas das perguntas e atendendo as demandas dos estudantes. O resultado dessa aplicação, a análise dos projetos na formação docente bem como os relatos de usos do Kahoot feitos por outros professores durante o curso apresentaremos mais adiante.

\section{BREVE NOTA ACERCA DO KAHOOT}

A palavra Kahoot vem do inglês "in cahoots" cujo significado é parceria. E é justamente a colaboração a principal característica do dispositivo criado em 2016 pelos noruegueses Johan Brand, Jamie Brooker e Morten Versvik por meio de um projeto da Universidade Norueguesa de Ciência e Tecnologia. Sua utilização em sala de aula permite a união dos alunos por meio dos smartphones, tablets e/ou computadores.Dessa forma, o ambiente interativo pode se caracterizar como um gameplay.

Segundo informa o site do dispositivo (KAHOOT, 2020), ele pode ser usado para revisão de conteúdos; "quebrar gelo" proporcionando uma experiência divertida; testar conhecimentos; fazer pesquisas e promover debates; estimular interação e trabalho em equipe; criar campeonatos; trabalhar com pessoas dispersas globalmente; introduzir 
conteúdos novos; permitir que os estudantes também criem situações de aprendizagem; e desenvolver outros professores.

\section{Figura 1 - Página Inicial do Kahoot}

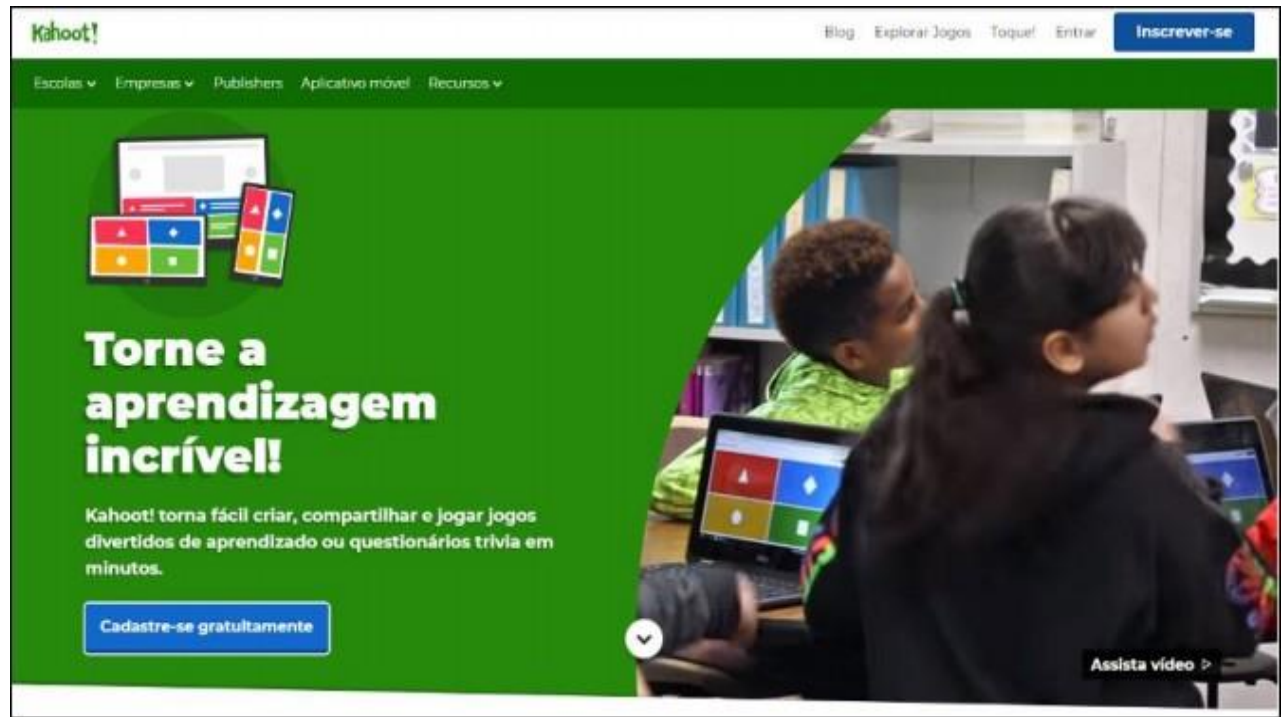

Fonte: Kahhot (2020)

O dispositivo é gratuito e possui características de um jogo digital, com regras e atribuições de pontuação para os estudantes que responderem as perguntas de forma correta e rápida. Ele permite a criação de Quizzes interativos exigindo apenas acesso à internet, a criação de uma conta na qual o professor poderá criar questionários de múltipla escolha e compartilhá-los com os alunos, que respondem de seus celulares ou tablets.

Além do Quiz, que se utiliza de temporizador para resposta de cada uma das perguntas e atribuição de pontuação aos acertos, o Kahoot oferece também as funções: Jumble: conjunto de perguntas de ordenamento em que os estudantes devem acertar a ordem correta em cada uma das perguntas feitas pelo professor; Discussion: para realização de debates e perguntas abertas; e Survey: para a realização de perguntas com temporizador, sem a atribuição de pontuação nas respostas dadas pelos estudantes. 


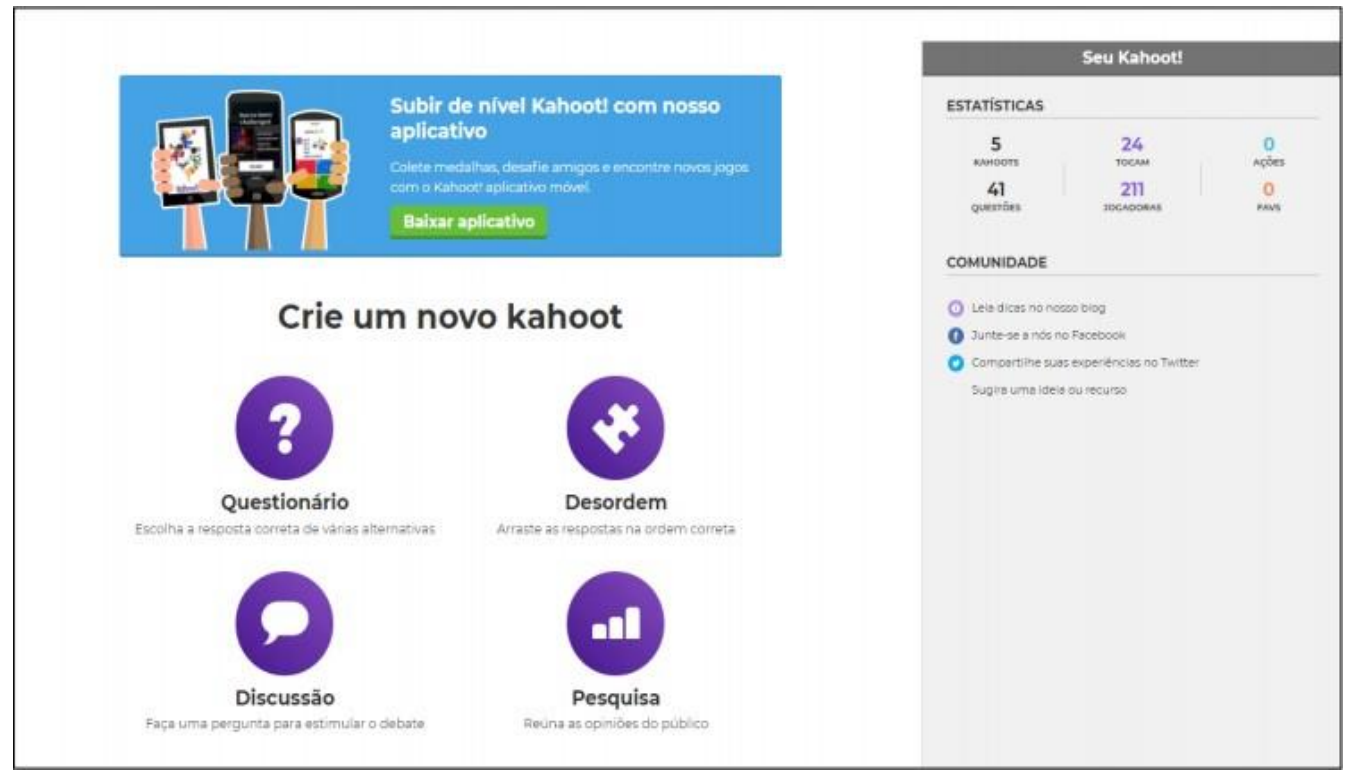

Fonte: Kahoot (2020)

O quiz é o mais utilizado por conta da pontuação contabilizada a partir dos acertos e do tempo gasto para responder as questões. A vertente Quiz potencializa aulas animadas e competitivas, fomentando aprendizagens significativas nos alunos, por meio da utilização da vertente "jogo" e da competição oferecida pelo dispositivo, dentro de um contexto educativo (GUIMARÃES, 2015, p. 204).

Para aplicar a dinâmica utilizando o Kahoot é necessário um dispositivo centralizador (computador ou notebook) que vai exibir as questões e no qual o professor inicia a competição bem como o tempo de resposta para cada questão. Os jogos na modalidade quiz podem ser síncronos ou assíncronos, e para jogá-los é preciso acessar ao jogo criado a partir de um PIN, isto é, um código que permite o acesso ao ambiente virtual. Embora exista a possibilidade de aplicar o jogo de forma assíncrona, ou seja, emdiferentes locais, o desejável é a realização em grupo para que o engajamento sejamaior.

Nesse sentido, o professor pode promover atividades tanto no laboratório de informática, quanto dentro de sala de aula caso os alunos tenham dispositivos móveis (celulares, tablets, notebook) e acesso à internet utilizando para isso o retroprojetor para facilitar a exibição das questões. O Kahoot está disponível apenas em inglês, mas com possibilidade de tradução com uso do Google Tradutor instalado no browser Google 
Chrome. O game pode ser respondido no celular nos sistemas operacionais Android e iOS.

Figura 3 - Questões e respostas no Kahoot

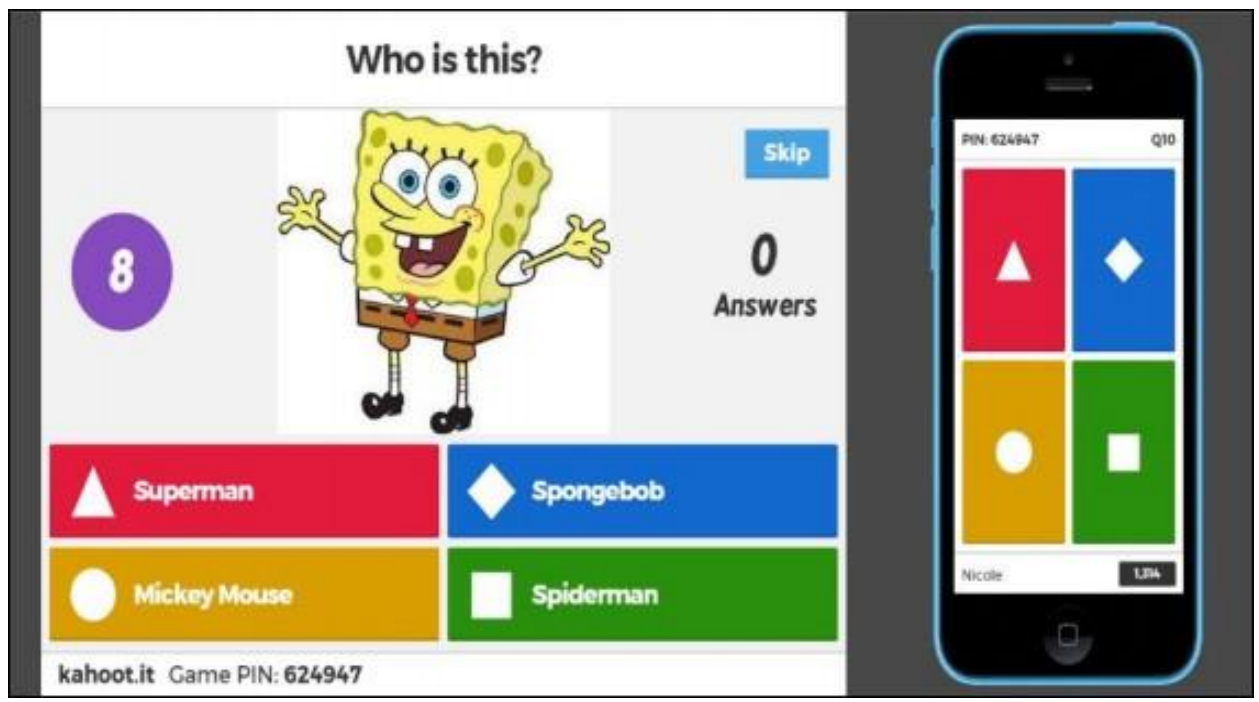

Fonte: Kahoot (2020)

O game pode ser jogado de forma individual ou em competição entre grupos. $\mathrm{Na}$ dinâmica, ganha mais pontos quem responder certo e em menor tempo. Depois de respondidas as questões, um ranking é gerado e ajustado a cada nova interação perguntaresposta. Finalizado o quiz, o dispositivo mostra a classificação de todos os estudantes e apresenta os três mais bem colocados.

Portanto, fica claro a combinação da dinâmica de jogo com os benefícios dos sistemas de resposta dos alunos ao ser criado um ambiente de estimulação e motivação propício para o engajamento dos estudantes no processo de aprendizagem. Na experiência de jogo há uma interação emocional de perda e ganho que os envolve e os faz ter atenção. A partir dessas percepções, vamos averiguar na seção seguinte como o assunto tem sido tratado nos estudos acadêmicos feitos e publicados. 


\section{REVISÃO SISTEMÁTICA DE LITERATURA}

Com o propósito de trazer aspectos relevantes sobre o tema e fundamentar teoricamente este trabalho, recorremos ao estado da arte acerca das questões aqui abordadas por meio de pesquisas bibliográficas em artigos, dissertações e teses. Como bases de dados escolhemos: a Biblioteca Digital de Teses e Dissertações, o Banco de Teses e Dissertações da Capes, o Portal de Periódicos da Capes e o Google Escolar.

A revisão de literatura é sempre recomendada para o levantamento da produção científica disponível e para a (re)construção de redes de pensamentos e conceitos, que articulam saberes de diversas fontes na tentativa de trilhar caminhos na direção daquilo que se deseja conhecer (GOMES; CAMINHA, 2014, p. 396). Alinhados a este pensamento, Medina e Pailaquilén (2010) quando enfatizam que "os pesquisadores precisam da RSL para resumir os dados existentes, refinar hipóteses, estimar tamanhos de amostra e ajudar a definir agendas de trabalhos futuros."

Carvalho, Oliveira e Ribeiro (2011) destacam que esse procedimento indica a qualidade de conhecimento científico, reconhece a produção intelectual de outros pesquisadores e, principalmente, traz como complemento conhecimentos jáestabelecidos e nos ajuda a identificar lacunas de pesquisa. Nesse sentido, analisamos o conteúdo dos trabalhos selecionados e procuramos identificar neles pontos em comum que nos ajudaram a melhor compreender o tema deste artigo.

Como critério de filtragem, estabelecemos o período temporal de 2015 a 2020, determinamos que seriam buscadas apenas publicações nacionais, definimos Educação como área de concentração e elegemos como descritores os termos Kahoot e educação. Dessa busca foram identificados 30 trabalhos: 11 dissertações, 19 artigos e nenhuma tese. Para refinar um pouco mais a busca, estabelecemos como critério secundário, a partir da leitura dos títulos e dos resumos que seriam selecionados apenas os estudosque fizessem uma discussão direcionada ao Kahoot e tivessem um melhor alinhamento ao tema deste trabalho, que é discutir o uso do dispositivo dentro de uma ideia de tática docente. 
Quadro 1 - Trabalhos selecionados

\begin{tabular}{|c|c|c|}
\hline AUTOR(RES) & TÍTULO DO TRABALHO & ANO/NÍVEL \\
\hline BARBOSA, R. L. & $\begin{array}{l}\text { Web 2.0, APP e tecnologias móveis na avaliação da } \\
\text { aprendizagem: um estudo sobre o Kahoot }\end{array}$ & 2019/Dissertação \\
\hline PITOMBEIRA, J. R. & $\begin{array}{l}\text { O Kahoot no ensino de álgebra nos anos iniciais do } \\
\text { Ensino Fundamental }\end{array}$ & 2020/Dissertação \\
\hline CRESPO, A. H. & $\begin{array}{l}\text { Elementos do estado de fluxo durante atividades com } \\
\text { Kahoot: um estudo de casos múltiplos em aulas de } \\
\text { alemão }\end{array}$ & 2019/Dissertação \\
\hline LIMA JUNIOR, E. F. & $\begin{array}{l}\text { "E-storia": O ensino de história e os jogos digitais - } \\
\text { um estudo de caso através da plataforma Kahoot }\end{array}$ & 2019/Dissertação \\
\hline MARCANDELI, S. & $\begin{array}{l}\text { Gamificação em aplicativos para a educação:estratégias } \\
\text { para o processo educativo }\end{array}$ & 2020/Dissertação \\
\hline $\begin{array}{l}\text { MONTEIRO, J. } \\
\text { RODRIGUES, A. S.; } \\
\text { PINHEIRO, S. C. }\end{array}$ & $\begin{array}{l}\text { C.; Comunicação, educação e tecnologias: reflexões } \\
\text { interdisciplinares sobre o Kahoot }\end{array}$ & 2019/Artigo \\
\hline $\begin{array}{l}\text { BEZERRA, C. L.; } \\
\text { LIMA, D. J. }\end{array}$ & $\begin{array}{l}\text { Kahoot: uma ferramenta didático-pedagógica para o } \\
\text { ensino de educação ambiental }\end{array}$ & 2020/Artigo \\
\hline $\begin{array}{l}\text { COELHO, P. } \\
\text { MOTTA, E. L; } \\
\text { CASTRO, F. P. }\end{array}$ & $\begin{array}{l}\text { M.; Reflexões interdisciplinares sobre o aplicativo } \\
\text { Kahoot no ambiente educacional }\end{array}$ & 2017/Artigo \\
\hline $\begin{array}{l}\text { COSTA, T. C.; } \\
\text { OLIVEIRA, I. } \\
\text { SANTOS, L. M. }\end{array}$ & $\begin{array}{l}\text { Uso do aplicativo Kahoot: uma ferramenta } \\
\text { P.; pedagógica para as aulas de química por } \\
\text { intermediação tecnológica }\end{array}$ & 2019/Artigo \\
\hline $\begin{array}{l}\text { CASTILHO, W. } \\
\text { SARAIVA, L.M.; } \\
\text { NOGUEIRA, F. R. }\end{array}$ & $\begin{array}{l}\text { S.; A utilização do aplicativo Kahoot como metodologiade } \\
\text { avaliação para a inserção da física das radiações } \\
\text { no Ensino Médio. }\end{array}$ & 2020/Artigo \\
\hline
\end{tabular}

Fonte: elaborado pelos autores (2020)

Da leitura dos resumos, trouxemos o entendimento de que o Kahoot apresenta elementos positivos ao processo de ensino aprendizagem a partir das diversas abordagens realizadas. Ele se apresenta como possibilidade de uso nas várias áreas do conhecimento e em todos os níveis de ensino, além de despertar a curiosidade, estimular o engajamento dos alunos, aumentar o interesse pelos estudos e tornar o processo de avaliação da aprendizagem mais motivacional, colaborativo, interativo e significativo.

De acordo com Bezerra e Lima (2020, p. 10), o uso do Kahoot dentro do ensino de educação ambiental trouxe uma contribuição significativa ao possibilitar que o estudante aprendesse de forma interativa e viabilizou aos docentes uma participação mais ativa. Já o feedback imediato do game permitiu a Barbosa (2019, p. 72) identificar as principais dificuldades dos alunos da disciplina de Geometria Analítica e Álgebra Linear e, com isso, traçar uma estratégia de avaliação formativa processual adaptada ao estudante. 
Pitombeira (2020) se predispôs a averiguar como seria o desempenho dos estudantes com e sem a utilização do Kahoot em atividade com álgebra e concluiu que o aproveitamento nas resoluções das questões foi melhor quando foi usado o dispositivo. $\mathrm{O}$ entusiasmo dos estudantes também foi uma das principais características identificadasna experimentação estudada por Castilho, Saraiva e Nogueira (2020) ao trabalharem Física das Irradiações com os estudantes. De acordo com os autores, essa estratégia didática possibilitou uma melhor aprendizagem dos estudantes, com mais de $60 \%$ de aproveitamento, constituindo-se assim, protagonistas da própria aprendizagem.

Outra evidência apresentada foi a de o Kahoot além de possibilitar ao professor uma nova proposta de avaliar os alunos de forma mais pertinente, aproximou o docente do discente durante o processo avaliativo (COELHO; MOTTA; CASTRO, 2017, p. 27). Entretanto, segundo Costa, Oliveira e Santos (2019) é preciso que o professor saiba trabalhar a intencionalidade pedagógica nesse cenário digital e que desperte mais interesse dos estudantes. Segundo as pesquisadoras, a inserção da tecnologia por si só não é o suficiente, sendo necessário que os docentes conheçam mais os usos dastecnologias educacionais digitais de forma ativa e efetiva.

Crespo (2019), por sua vez, destaca que existem aspectos positivos na utilização dos dispositivos digitais, como nas experimentações que estudou acerca do Kahoot. Porém, muitos docentes se sentem desmotivados a utilizá-los devido à estrutura tecnológica nas escolas. A denúncia destas condições materiais alinha-se à conclusão de Monteiro, Rodrigues e Pinheiro (2019) quando afirmam que muitos professores ainda resistem ao uso, principalmente por não se sentirem preparados para utilizá-los para fins pedagógicos. Lima Junior (2019) também corrobora com essa ideia e acrescenta que a tecnologia por si só não gera bons resultados se o professor não souber fazer bom uso pedagógico dela.

Por fim, ao avaliar aplicativos educacionais, Marcandali (2020, p. 58) chegou ao entendimento de que a gamificação aliada à educação traz inúmeros benefícios tanto para os estudantes quanto para os professores, facilitando o aprendizado e mantendo os alunos motivados. Aliados a este pensamento, cremos que trabalhar com essa linguagemna sala de aula pode fazer com que o aluno se engaje, o professor se torne mediador e a aprendizagem seja colaborativa. 
Enxergamos a formação continuada docente como um caminho capaz de oportunizar essa aproximação com os dispositivos digitais e seus usos pedagógicos. Nos estudos que aqui analisamos não identificamos nenhuma abordagem direcionada a formação de professores para o uso do Kahoot e/ou a linguagem gamificada. Portanto, o dispositivo estar inserido no curso UFDOPA trouxe originalidade oportunizando aos professores conhecerem práticas docentes diferenciadas a partir dessas novas linguagens.

\section{ANÁLISE E DISCUSSÃO DOS DADOS}

Conforme anunciamos no texto introdutório deste artigo, os dados produzidos para as averiguações aqui propostas são compostos por Diário de Bordo com os registros da observação não-participante do curso de formação docente em metodologia da transmidiação e da aplicação da dinâmica com o Kahoot em uma turma do $5^{\circ}$ ano do Ensino Fundamental I, a entrevista semiestruturada aplicada pela professora da turma escolhida, análise dos depoimentos dos estudantes feitos por escrito à docente como parte da atividade pedagógica realizada e os projetos apresentados pelos professores no curso UFDOPA que contemplaram o Kahoot.

O ponto de partida da análise deste estudo foi as propostas de experimentações feitas pelos professores cursistas durante a formação, bem como os relatos deles acerca das atividades realizadas. Dentre os Quizzes realizados houve abordagenscontemplando: o reconhecimento de si e do outro, o corpo humano, estratificação social na idade média, adição e subtração; multiplicação, comparativo e superlativo em inglês, ortografia, globalização, isomeria (Química), reconhecimento dos objetos, acentuação e Ciências. 
Figura 4 - Exemplo de um dos quizz aplicado

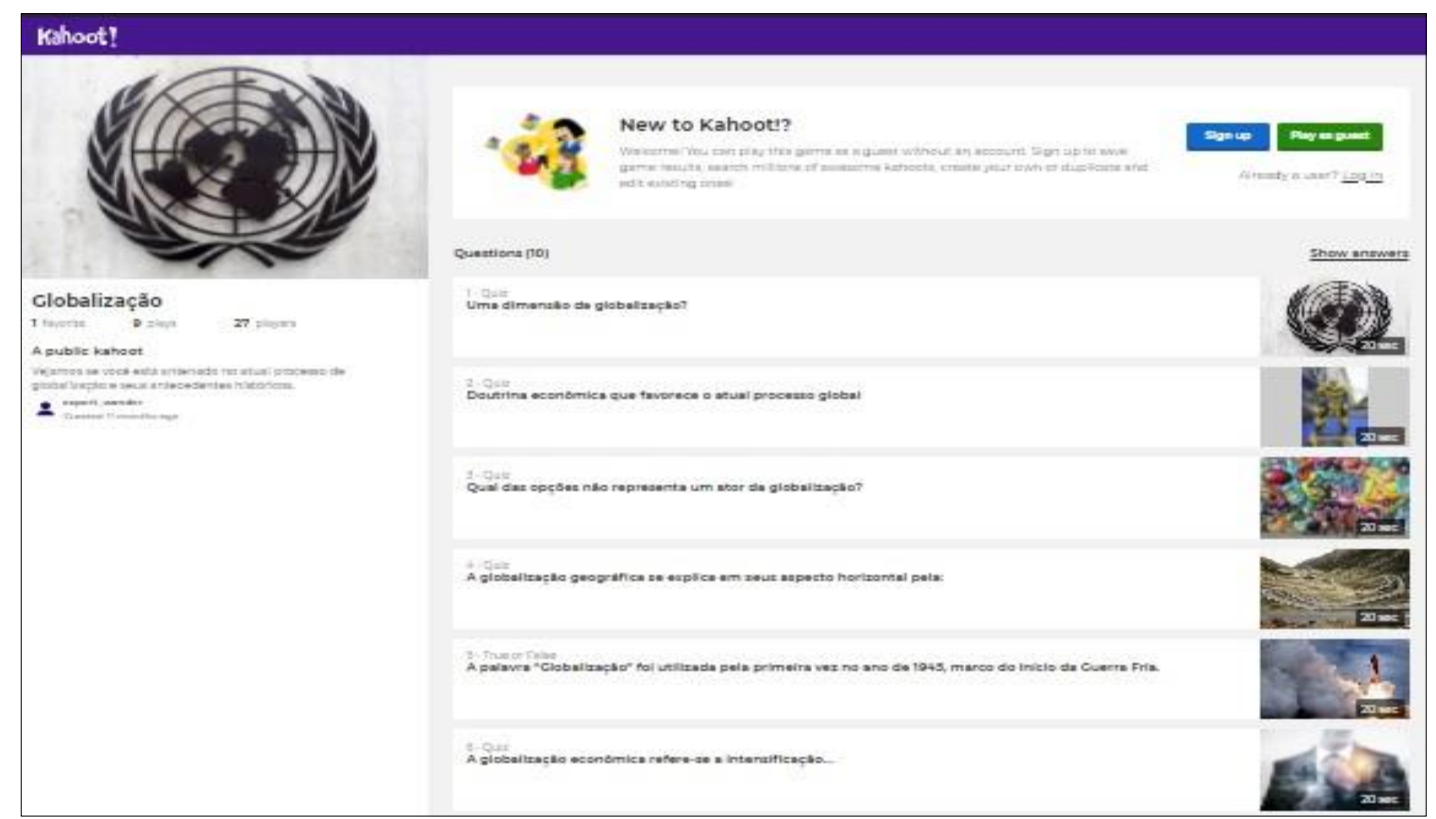

Fonte: AVA do curso UFDOPA

A tarefa realizada pelos professores cursistas consistia em criar uma conta uma conta no Kahoot, elaborar um jogo tipo quiz com no mínimo cinco questões, inserir em cada questionamento o tempo de resposta, adicionar (opcionalmente) fotos ilustrativas, aplicar o game para no mínimo de três estudantes e ao final fazer a verificação de desempenho e o ranqueamento dos participantes no site do Kahoot. Depois de realizadas as atividades, cada professor tinha que anexar o jogo no ambiente virtual de aprendizagem e compartilhar com os colegas na aula presencial as experiências e os resultados.

No que diz respeito as experiências dos professores com as atividades, eles relataram nas aulas presenciais do curso que observaram nos estudantes uma motivação maior pela dinâmica e uma euforia não vista nas abordagens tradicionais de ensino. Alguns sinalizaram dificuldade em utilizar o dispositivo pela falta de habilidade com as tecnologias e outros descreveram como empecilho a falta de estrutura tecnológica em suas escolas fazendo com que utilizassem o próprio equipamento (smartphone e notebook) para não deixar de realizar a atividade. Também compartilharam que nas aulas posteriores a experimentação, os estudantes fizeram novos pedidos para a realização de outras atividades com o Kahoot. 
Nos projetos finais do curso, quatro projetos pedagógicos também contemplaram o Kahoot. Foram propostos quizzes para memorização dos avatares da turma feitos no aplicativo Bitmoji, também ensinado no curso, e fixação de conteúdos já vistos; para sondagem de conhecimento acerca de geopolítica na aula de Geografia no EnsinoMédio; na revisão de Matemática e Português (ortografia) na turma do $3^{\circ}$ ano do Ensino Fundamental e como avaliação do conteúdo Modal Verbs na disciplina de LínguaInglesa.

Para a observação não participante da experimentação em sala de aula foi escolhida a turma de $5^{\circ}$ ano do Ensino Fundamental I da Escola Classe 42 de Taguatinga, composta por 27 alunos com idade entre 10 e 12 anos. A escolha desselócus de pesquisa se deu pelo fato de a professora estar trabalhando com um maior número de dispositivos digitais e, portanto, apresentava melhores condições para produção de dados em uma das pesquisas acadêmicas realizadas a partir da formação docente.

Para a realização da dinâmica com o Kahoot a professora utilizou três aulas distintas dentro do planejamento da atividade. A primeira aula foi utilizada para a explicação do conteúdo de Ciências que estava sendo trabalhado, a seguinte para ensinar os estudantes como explorar o dispositivo Kahoot e a última aula foi dedicada a dinâmica de revisão do conteúdo para a prova da disciplina. Para realizar foi necessário montar uma estrutura na sala de aula com computador e retroprojetor.

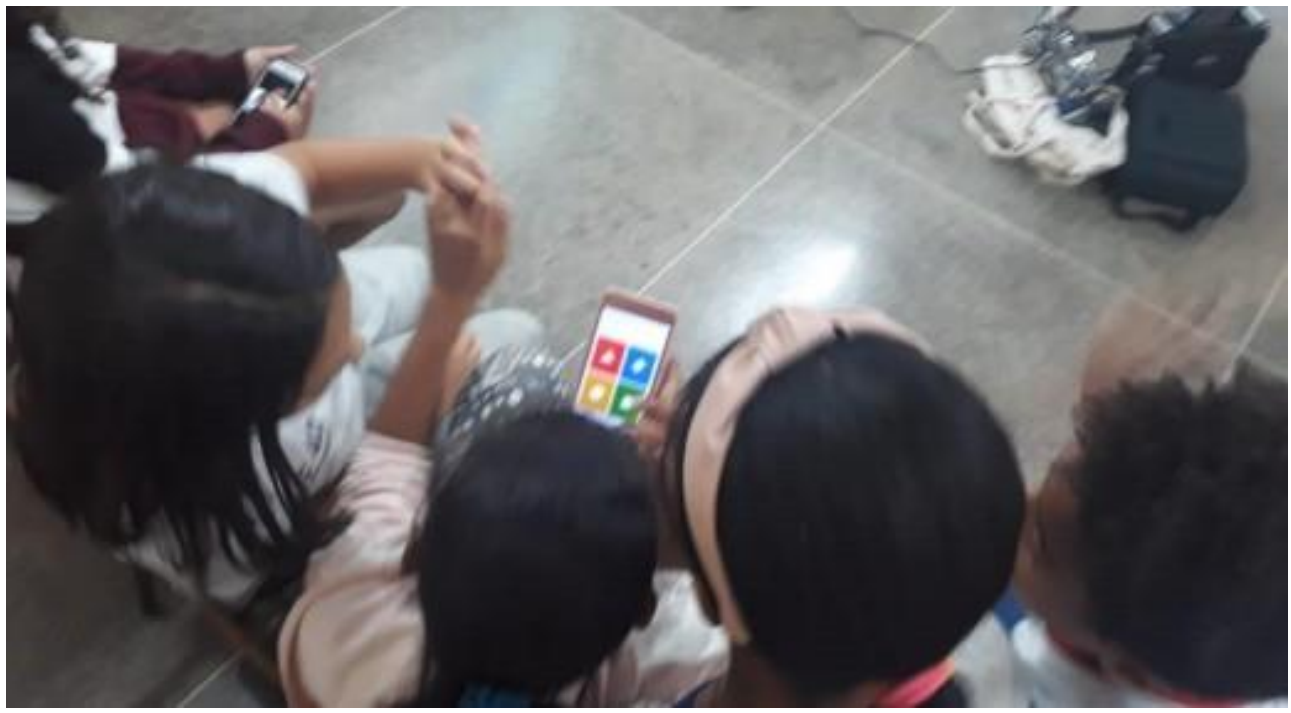


Fonte: arquivo pessoal da professora da turma

Antes da realização da atividade, a professora informou aos pais que aconteceria tal dinâmica e solicitou a autorização para que os filhos que tinham aparelho celular que eles pudessem levá-los para a escola para serem utilizados com essa finalidade. Nem todos tinham aparelho móvel com conexão na internet e, por essa razão, a professora os dividiu em quatro grupos. A partir da observação não participante foi possível perceber o alto nível de motivação, atenção e engajamento. A cada acerto muitas comemorações bem como um claro trabalho cooperativo entre os grupos para garantir um bom desempenho. Neste processo, a professora atuou como mediadora estimulando os mais retraídos e fazendo um controle do acaloramento dos mais animados.

Além do Kahoot, a professora trabalhou com os estudantes atividades a partir de outros dispositivos digitais para produção de histórias em quadrinhos e vídeos. Ao final solicitou que cada estudante fizesse um parágrafo de texto escrito, sem se identificar, falando como foi a experiência e que o entregassem a ela como parte da atividade. $\mathrm{O}$ material foi compartilhado para fins de pesquisa e submetido ao Iramuteq com opropósito de compreender as impressões dos estudantes. A seguir apresentamos o esquema gráfico da nuvem de palavras e, na sequência, as análises dela.

Figura 6 - Nuvem de palavras acerca do uso dos dispositivos

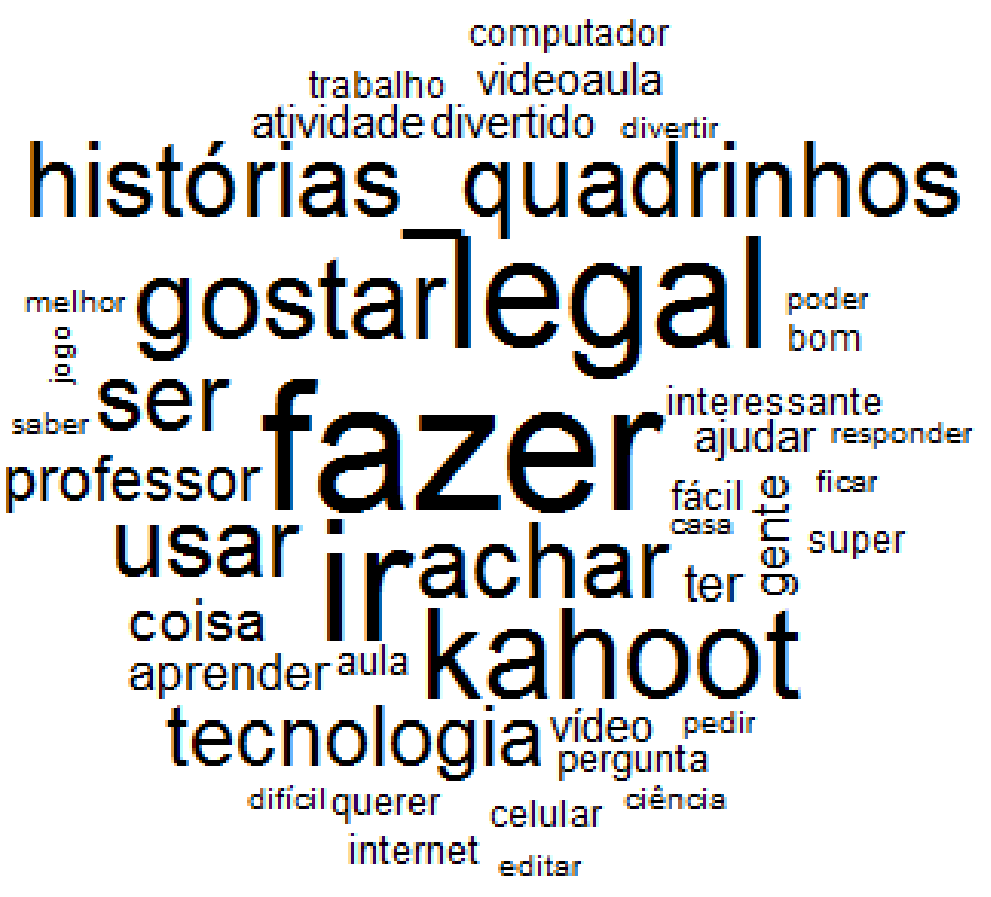


Do corpus de texto analisado, a palavra fazer (38) foi a que mais se destacou, rodeada das expressões: ir (35), legal (32), Kahoot (25), gostar (22), achar (20), histórias em quadrinhos (20), ser (18) e usar (18). Dessa composição gráfica pudemos inferir que os estudantes se identificaram com o uso dos aplicativos e do trabalho com as narrativas. Nesse contexto, sinalizaram a preferência pelo Kahoot, seguido da produção de HQs e, por último, as produções de videoaulas. Entendemosque nesse contexto mostrado na figura o fazer sugere uma ideia de realizar uma tarefa e associado ao verbo ir dá uma noção de proatividade.

Por outro lado, na região periférica do gráfico apareceu professor (10), indicando estar deslocado do discurso central dos estudantes. Outros termos, como aula (05), trabalho (04), difícil (03) e pedir (03) também apareceram com menor frequência, apresentando-nos indicativos de que as atividades foram desafiadoras em menor intensidade, atuaram mais autônomos e o contexto de sala não teve significância.

Dessa leitura, podemos pensar que adoção de experiências de aprendizagem com os dispositivos e suas linguagens podem recompor as práticas de ensino e aprendizagem de maneira mais atrativa dando assim protagonismo aos estudantes. Além disso, a experiência com os dispositivos e suas linguagens são importantes na construção de conteúdo significativo para os estudantes, alinhados ao seu contexto de produção de sentidos e ideias. Conforme explica Kenski (2007), essa experiência promovida pelas novas tecnologias de comunicação na educação provoca novas mediações entre a abordagem do professor, a compreensão do aluno e o conteúdo veiculado.

\begin{abstract}
A imagem, o som e o movimento oferecem informações mais realistas em relação ao que está sendo ensinado. Quando bem utilizadas, provocam a alteração dos comportamentos dos professores e alunos, levando-os ao melhor conhecimento e maior aprofundamento do conteúdo estudado (KENSKI, 2007, p. 45).
\end{abstract}

Atribuindo outro tratamento aos dados trazidos pela nuvem, utilizamos a análise de similitude com a finalidade de tornar mais complexa a interpretação do discurso das 
estudantes e percebermos os sentidos da escolha e do uso das palavras. Do conteúdo analisado foram registradas 1.141 ocorrências, ou seja, repetições de palavras com uma média de 45 para cada um dos depoimentos dos estudantes.

Figura 7 - Similitude das impressões das experimentações 


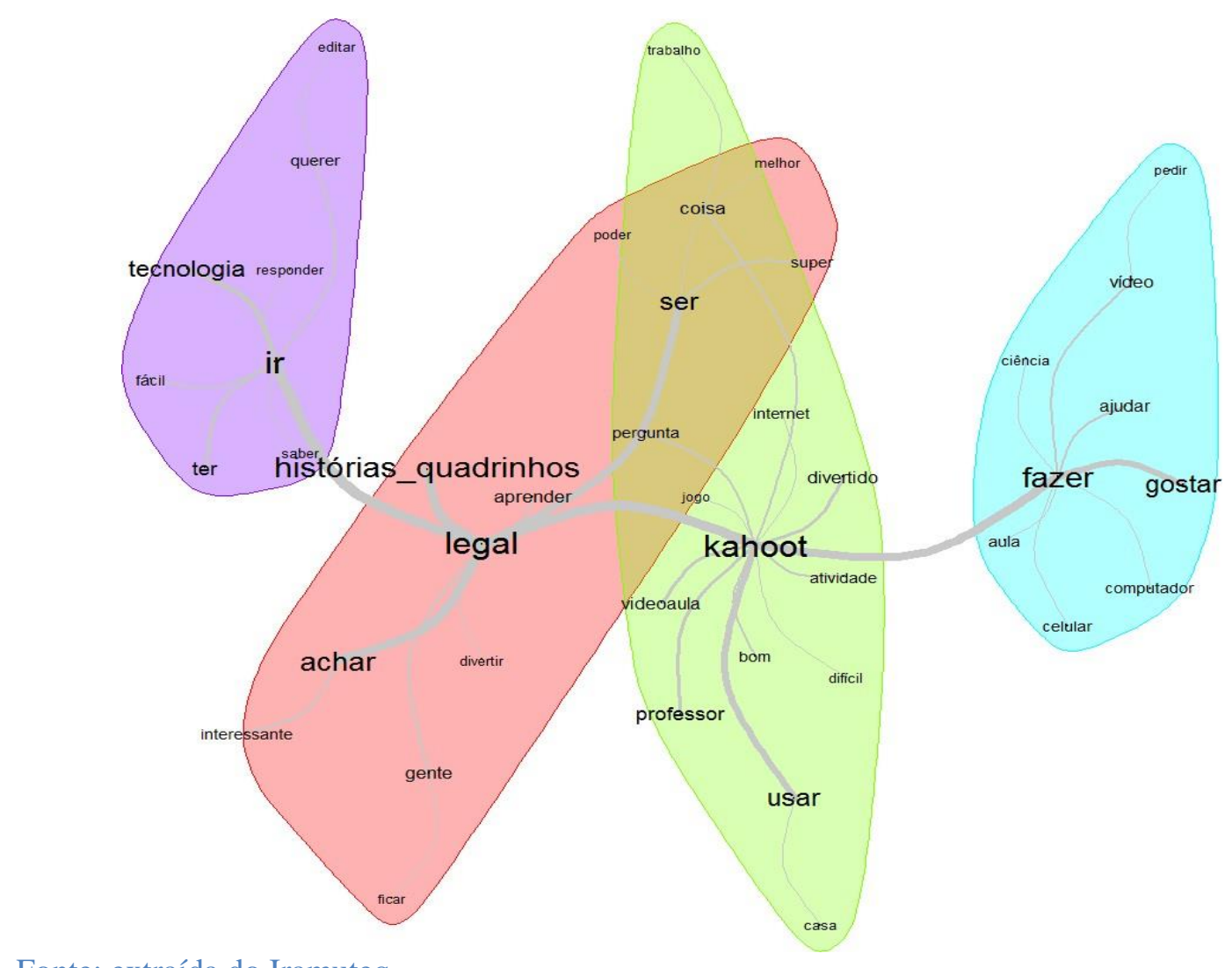

Fonte: extraída do Iramuteq

Do quadro geral da similitude, pudemos observar que Kahoot (25) no centro das conexões dos quatro núcleos formados e com o maior número de ramificações. A ele se conectou expressões, como usar (18), professor (10), divertido (06), atividade (06), bom (04), pergunta (05), internet (05), difícil (03) e jogo (03), levando-nos a uma interpretação de que utilizar o dispositivo em uma dinâmica de sala de aula repercutiu positivamente, tendo em vista a dinâmica de games, apesar da dificuldade para alguns.

Em um segundo núcleo, a palavra Kahoot ligou-se ao termo fazer (38), que interligou a gostar (22), ajudar (06), aula (05), computador (04), celular (04), ciência (03) e pedir (03), corroborando também com o entendimento de identificação dos estudantes com a experimentação envolvendo os dispositivos e os aparatos tecnológicos para trabalhar um conteúdo pedagógico. A presença do celular, nesse contexto pedagógico, mostra-se atrativo aos jovens, considerando que, em 2018, 93\% deles utilizaram o smartphone para acessar a internet (COMITÊ GESTOR DA INTERNET NO BRASIL, 2019, p. 112). 
Entendemos que essa preferência pelo Kahoot encontra justificativa no fato da gamificação aproximar a escola e a aprendizagem do universo dos jovens que usa esse recurso no celular, no computador e pela internet com outros jogadores virtuais. "O processo de gamificação pode se converter num experimento válido para a temática da educação na medida em que consegue atrair o aluno para o processo de construção de conhecimento" (LIMA JUNIOR, 2019, p. 35).

Essa identificação dos estudantes também é retirada da fala de Guimarães (2015), ao dizer que a interatividade e a oportunização de aulas animadas e competitivasmotivam os estudantes a se prepararem previamente, numa perspectiva mais autodidata $\mathrm{e}$ independente. Esse tipo de aplicativo é especialmente útil para a implementação de uma aula invertida - flipped room - que tem por principais pressupostos o estudo autônomo e prévio do aluno. (GUIMARÃES, 2015, p. 204).

O estudante Jerivá (2019) se enquadra nesse perfil tendo relatado que para ele "usar o Kahoot foi muito legal, mais que as histórias em quadrinhos, porque ele é legal e não é demorado." A mesma preferência manifestou a estudante Pereira (2019), ao compartilhar que para ela "o Kahoot teve um papel importante por ter ajudado bastante na revisão para a prova de ciências que fez com que pudesse gabaritar a prova”.

A devolutiva dos estudantes alinha-se a percepção da professora da turma, que aqui daremos o nome fictício de Cristal. Segundo ela, os alunos apresentaram mais autonomia durante a execução das atividades, demonstrando um envolvimento maior. Por estas razões, a docente defende a utilização dos dispositivos digitais por propiciar mais possibilidades ao processo de aprendizagem, permitindo uma leitura mais dinâmica e em consonância com o desejo do aluno de se envolver.

Essa aula tradicional em que o professor só fala e o aluno só escuta é muito ultrapassada. Nossa realidade, hoje, é que temos um conteúdo do século XIX,professores do século XX e alunos do século XXI. Então tem muita coisa atrasada e, portanto, tudo aquilo que você busca para deixar a aula prazerosae interessante é muito bom (CRISTAL, 2019, s.p.). 
Além desse descompasso mencionado por Cristal, existem as dificuldades com a infraestrutura na escola que retardam ou mesmo impedem os docentes de explorar tal potencial. Na dinâmica realizada pela professora, foi necessário o uso do próprio notebook instalado na sala de aula, já que o laboratório de informática da escola não estava funcionando e só um computador estava em condições de uso.

Este contexto, segundo Cristal (2019), faz com que muitos professores resistam à implementação de ações que busquem a incorporação de novas práticas de ensino com uso das tecnologias e de novas metodologias. Essa resistência, segundo a docente está centrada na falta de condições técnicas nas instituições de ensino que é uma prerrogativa do Estado. "Como que o professor vai se interessar por usar tecnologia em sala de aula se toda essa tecnologia tem que ser providenciada por ele? É uma pena" (CRISTAL, 2019).

Muitas iniciativas do poder público foram implementadas ao longo dos últimos anos, entretanto, não se sustentaram, foram enfraquecendo com o tempo e perderam sua efetividade. Acreditamos que entre as razões para isso estão o descompasso entre os programas e políticas públicas e a necessidade real das instituições escolares; o foco na instrumentalização e não na formação continuada; e em capacitações voltadas para a operacionalização de equipamento e não para o uso mais amplo pedagogicamente. A seguir apresentamos alguns aspectos dos Programas de Governo para o uso das tecnologias nas escolas públicas de 1982 a 2017.

Quadro 2 - Panorama dos programas de governo

\begin{tabular}{|c|}
\hline EDUCAÇÃO COM COMPUTADORES - EDUCOM (1982) \\
\hline $\begin{array}{l}\text { Objetivo: Desenvolver pesquisa do uso educacional da informática e levar computadores às escolas } \\
\text { públicas. } \\
\text { Pontos fracos: poucas universidades brasileiras se envolveram e houve dificuldades com a aplicaçãodo } \\
\text { projeto nas escolas por conta de mudanças políticas ao fim do governo militar. }\end{array}$ \\
\hline PROGRAMA NACIONAL DE INFORMÁTICA EDUCATIVA - PRONINFE (1989) \\
\hline $\begin{array}{l}\text { Objetivo: incentivar a capacitação dos profissionais da educação no domínio da tecnologia educativa,em } \\
\text { todos os níveis e modalidades de ensino. } \\
\text { Pontos fracos: custo elevado para aquisição de equipamentos para suprir todas as escolas e a } \\
\text { disponibilização de poucos softwares educativos para as escolas. }\end{array}$ \\
\hline PROGRAMA NACIONAL DE INFORMÁTICA NA EDUCAÇÃO - PROINFO (1997) \\
\hline
\end{tabular}




\begin{tabular}{l} 
PROGRAMA DE BANDA LARGA NAS ESCOLAS - PBLE (2008) \\
Objetivo: conectar todas as escolas públicas urbanas à internet por meio de tecnologias que propiciem \\
qualidade, velocidade e serviços para incrementar o ensino público no País. \\
Pontos fracos: problemas de conectividade e velocidade da rede; * muitas escolas de área rural e \\
urbana não participam do programa. \\
\hline PROGRAMA UM COMPUTADOR POR ALUNO - PROUCA (2012) \\
Objetivo: intensificar as Tecnologias da informação e comunicação (TIC) nas escolas. \\
Pontos fracos: falta de estrutura física adequada aos professores e problemas de conectividade. \\
\hline TABLET EDUCACIONAL (2012) \\
Objetivo: disponibilizar conteúdos didáticos por meio digital. \\
Pontos fracos: não entrega de equipamentos para os alunos; problemas de conectividade; pouco \\
espaço de armazenamento de informação. \\
EDUCAÇÃO CONECTADA (2017) \\
\hline $\begin{array}{l}\text { Objetivo: poiar a universalização do acesso à internet de alta velocidade e fomentar o uso pedagógicode } \\
\text { tecnologias digitais na Educação Básica. } \\
\text { Pontos fracos: ainda não mensurados por se encontrar em fase de expansão }\end{array}$ \\
\hline
\end{tabular}

Fonte: Elaborado pelos autores (2020)

Segundo Cristal (2019), essa pouca efetividade dos programas faz com que, na prática, as iniciativas partam da maioria dos docentes que buscam táticas para melhorar o processo de ensino-aprendizagem com o uso das tecnologias. Apesar disso a docente, defende que a adoção de tais práticas tem em vista o resultado apresentado com a realização de práticas docentes diferenciadas.

\section{CONSIDERAÇÕES}

Portanto, do entrelaçamento de falas, dados e evidências identificamos questões como, por exemplo, a alteração da dinâmica de ensino com o uso do dispositivo, houve aumento no engajamento e os estudantes se mostraram mais integrados ao processo, a precariedade das condições físicas para a realização de novas práticas e o reconhecimento da necessidade da formação docente continuada voltar-se à utilizaçãode diferentes linguagens em sala de aula.

O kahoot, conforme indicado pelos estudos que trouxemos como referência, se confirmou como uma alternativa viável para práticas didáticas alinhadas ao desejo dos estudantes. Além disso, revelou que a partir do seu uso há um melhor engajamento dos 
alunos, as aulas ficam mais dinâmicas e atrativas, os alunos participam mais e até melhoraram seu desempenho. Desta forma, podemos dizer que a inserção de outros métodos às práticas e metodologias tradicionais torna a aprendizagem mais atrativa aos estudantes.

Consideramos que uma formação docente continuada direcionada ao uso de linguagens como o Kahoot em sala de aula é uma tática possível para melhorar aspectos da educação tradicional, trazendo práticas diferenciadas ao processo de ensino e aprendizagem. Na revisão sistemática de literatura não identificamos estudos que abordassem a formação de professores para o uso da gamificação, neste exemplo o Kahoot. Isso nos indica que há uma brecha para minimizar a carência de formação continuada para os professores das escolas públicas para atender a essas demandas.

Ficou evidenciado ainda que o trabalho pedagógico com as linguagens digitais, entre elas a gamificação, é um caminho possível para a construção de um processo formativo alinhado às demandas dos estudantes e de uma educação libertadora que, segundo Freire (1996), "necessita que o educando crie suas representações do mundo, pense as estratégias para solução de seus problemas, aprenda e se compreenda como sujeito da história". Acreditamos que o uso dos multiletramentos é algo que aponta para o novo, para a diferenciação e não apenas para a repetição (cópia), trazendo desse modo o estudante para o processo de ensino.

Salientamos que há inúmeros outros dispositivos além do Kahoot e outros tantos virão. Porém, é importante ressaltar que a incorporação de novos elementos na educação contribui para que a Educação possa continuar atendendo às demandas exigidas pelos sujeitos culturais do seu tempo e do seu contexto social. Além disso, é preciso criar causas e condições para isso se efetivar de fato equipando adequadamente as escolas, orientar os docentes quanto aos usos pedagógicos dos dispositivos digitais e promover políticas públicas para esta familiarização.

Como conclusão, afirmamos que o trabalho com as linguagens digitais a partir do uso dos dispositivos se apresenta com uma tática capaz de direcionar para o novo, para a diferenciação e não apenas para a repetição. Entendemos que a gamificação é só uma das várias possibilidades da exploração dessas linguagens, mas que se mostra potente como vimos neste artigo. Dentre os possíveis caminhos do trabalho com metodologia da transmidiação, que trabalha com essas linguagens, estão a inserção na educação especial, 
a aplicação na formação acadêmica nos cursos superiores, a utilização na alfabetização visual e escrita na perspectiva dos multiletramentos, a alfabetização multimodal e o uso pedagógico para avaliar gêneros textuais, autoria, colaboração e formas escritas com as fanfics.

A conjuntura imposta pela pandemia da doença covid-19, causada pelo coronavírus, nos alertou para a necessidade da busca por novas táticas e as tecnologias digitais se tornam imprescindíveis. O computador se tornou a sala de aula e a interação, conversa agora tem que acontecer por meio de salas virtuais, lives, grupos de mensagem instantânea, teleaulas, programas gravados para TVs Educativas e plataformas de produção de conteúdo web. Nesse novo cenário, o professor teve de mediar os conhecimentos e os estudantes desenvolverem trabalhos colaborativos on-line $\mathrm{e}$ envolvendo ativamente a família no processo de aprendizagem.

Por fim, entendemos que é preciso debater e pensar novas metodologias e usos das tecnologias como apoio aos processos educacionais que estão a todo tempo se transformando e nos trazendo, enquanto educadores, novas demandas. A discussão do assunto não se esgotou neste artigo, tendo sido um recorte de um contexto maior. Entretanto, esperamos que a análise apresentada seja estímulo para outros debates e que deles surjam novas práticas sintonizadas com a realidade e a necessidade dos estudantes.

\section{REFERÊNCIAS}

AGAMBEN, G. O amigo \& o que é um dispositivo. Chapecó: Argos, 2015.

BARBERO, J. M. A comunicação na educação. Tradução Maria Immacolata Vassallo de Lopes e Dafne Melo. São Paulo: Contexto, 2014. 155 p.

BARBOSA, R. L. WEB 2.0, APP e tecnologias móveis na avaliação da aprendizagem: um estudo sobre o Kahoot. 2019. 88 f. Dissertação (Mestrado em Educação) - Pontifícia Universidade Católica de Minas Gerais, Belo Horizonte, 2019.

BEZERRA, C. L.; LIMA, D. J. Kahoot: uma ferramenta didático-pedagógica para o ensino de educação ambiental. Revista Encantar - Educação, Cultura e Sociedade, Bom Jesus da Lapada, v. 2, p. 1-12, jan/dez. 2020.

BRASIL. Núcleos de tecnologia educacional estão em todo o país. Quinta-feira, 18 de janeiro de 2017. Disponível em: <http://portal.mec.gov.br/ultimas-noticias/2101448895310/7590-sp-482187765>. Acesso em: 16 set. 2020. 
BRASIL. Portaria n ${ }^{\circ}$ 522, de 9 de abril de 1997. Criação do Programa Nacional de Informática na Educação. Brasília, 1997. Disponível em:

<http://www.dominiopublico.gov.br/download/texto/me001167.pdf >. Acesso em: 22 set. 2020.

BRASIL. Secretaria de Educação Média e Tecnológica. Programa Nacional de Informática Educativa. Brasília, DF: PRONINFE, 1994.

BRASIL. Decreto no 9.204, de 23 de novembro de 2017. Institui o Programa de Inovação Educação Conectada e dá outras providências. Diário Oficial da União, Brasília, DF, 24 nov. 2017. Disponível em: <http://educacaoconectada.mec.gov.br/35-oprograma/149-o-programahttp://educacaoconectada.mec.gov.br/35-oprograma/149-oprograma>. Acesso em: 16 set. 2020.

BRASIL. Lei $\mathrm{n}^{\circ}$ 12.249, de 14 de junho de 2010. Institui o Regime Especial de Incentivos para o Desenvolvimento de Infraestrutura da Indústria Petrolífera nas Regiões Norte, Nordeste e Centro-Oeste - REPENEC; cria o Programa Um Computador por Aluno - PROUCA e institui o Regime Especial de Aquisição de Computadores para Uso Educacional - RECOMPE. Diário Oficial da União. Seção 1. Brasília, DF, 14 jun. 2010. p. 1. Disponível em: <https://www2.camara.leg.br/ legin/fed/lei/2010/lei-1224911-junho-2010-606678-publicacaooriginal-127512pl.htm>. Acesso em: 16 set. 2020.

BRASÍLIA. Câmara dos Deputados. Um Computador Por Aluno: A Experiência Brasileira. Coordenação de publicações, 2008. (Série Avaliação de políticas públicas).

CAMARGO, B.; JUSTO, A. Tutorial para uso do software Iramuteq. Florianópolis: UFSC, 2013. Disponível em: <http://www.iramuteq.org/documentation/fichiers/tutorielen-portugais>. Acesso em: 2 set. 2020.

CARVALHO, A. S.; OLIVEIRA, F. B.; RIBEIRO, E. A. Aspectos relevantes na confecção de uma revisão sistemática e metanálise. Evidência, Araxá, v. 7, p. 229- 236, 2011.

CASTILHO, W. S.; SARAIVA, L.M.; NOGUEIRA, R. A. A utilização do aplicativo kahoot como metodologia de avaliação para inserção da física das irradiações no ensino médio. Sajebtt, Rio Branco, UFAC, v, 7, n. 1, 2020.

COELHO, P. M.; MOTTA, E. L.; CASTRO, F.P. Reflexões interdisciplinares sobre aplicativa kahoot! no ambiente educacional. Acta Semiotica et Lingvistica, v. 22, n. 2, 2017.

COMITE GESTOR DA INTERNET NO BRASIL. Pesquisa sobre o uso da internet por crianças e Adolescentes no Brasil, 2017. 2018. Disponível em: <https://cetic.br/pesquisa/kids-online/publicacoes>. Acesso em: 16 ago. 2020.

COMITÊ GESTOR DA INTERNET NO BRASIL. Pesquisa sobre o uso da internet por crianças e Adolescentes no Brasil, 2018. 2019. Disponível em:

<https://cetic.br/pesquisa/kids-online/publicacoes>. Acesso em: 16 ago. 2020. 
COMITÊ GESTOR DA INTERNET NO BRASIL. Pesquisa sobre o uso das tecnologias de informação e comunicação nas escolas brasileiras. São Paulo, 2019. Disponível em: <https://www.cetic.br/media/docs/publicacoes/216410120191105/ tic_edu_2018_livro_eletronico.pdf $>$. Acesso em: 16 ago. 2020.

COSTA, T. C.; OLIVEIRA, I. P.; SANTOS, L. M. Uso do aplicativo kahoot: uma ferramenta pedagógica para as aulas de química por intermediação tecnológica. Brazilian Journal of Developement, Curitiba, v. 5, n. 9, p. 14321-14326, set. 2019.

Crespo, A. H. Elementos do Estado de Fluxo durante atividades com Kahoot!: um estudo de casos múltiplos em aulas de alemão. 2019191 f. Dissertação (Mestrado em Linguística e Lingua Portuguesa) - Universidade Estatual Paulista, Araraquara, 2019.

FARDO, Marcelo Luis. A Gamificação aplicada em ambientes de aprendizagem. RENOTE, v. 11, n. 1, 2013.

GOMES, I. S.; CAMINHA, I. O. Guia para estudos de revisão sistemática: uma opção metodológica para as Ciências do Movimento Humano. Movimento: Revista de Educação Física da UFGRS, Porto Alegre, v. 20, n. 1, p. 395-411, jan./mar. 2014. Disponível em: <https://seer.ufrgs.br/Movimento/article/view/41542〉. Acesso em: 17 set. 2020.

GUIMARÃES, D. Kahoot: quizzes, debates e sondagens. In. Ana Amélia A. Carvalho (Coord.). Apps para dispositivos móveis: manual para professores, formadores e bibliotecários. Brasília: Ministério da Educação, 2015.

KAHOOT!. Learning Games. [S.1.: s.n.], 2019. Disponível em: <https://kahoot.com/>. Acesso em: 16 ago. 2020.

KENSKI, V. M. (2012). Educação e tecnologias: o novo ritmo da informação. Rio de Janeiro: Papirus.design. ed. MIT Press, 2006. p. 15-29.

KENSKI, V. M. Tecnologias também servem para fazer educação. In: KENSKI, V. M. (Org.). Educação e tecnologias: o novo ritmo da informação. Campinas: Papirus, 2007.

LIMA JUNIOR, E. F. "E-storia": o ensino de história e os jogos digitais, um estudo de caso através da plataforma Kahoot. 2019. 108 f. Dissertação (Mestrado em História), Universidade Federal Rural de Pernambuco, Recife, 2019.

MARCANDALI, Sabrina. Gamificação em aplicativos para educação: estratégias para o processo educativo. 2020. 65 f. Dissertação (Mestrado em Mídia e Tecnologia) Universidade Estadual Paulista, Bauru, 2020.

MARTINS, D. M.; BOTTENTUIT JUNIOR, J. B. A Gamificação no Ensino de História: O Jogo "Legend of Zelda" na abordagem sobre o medievalismo. Holos, Instituto Federal de Educação, Ciência e Tecnologia do Rio Grande do Norte,v. 7, p. 299-321, 12 nov. 2016. Disponível em: <http://www2.ifrn.edu.br/ojs/index.php/HOLOS/article/view/1978>. Acesso em: 16 set. 2020 
MEDINA, E. U.; PAILAQUILÉN, R. M. B. A revisão sistemática e a sua relação com a prática baseada na evidência em saúde. Revista Latino-Americana de Enfermagem, Ribeirão Preto, v. 18, n. 4, p. 1- 8, jul./ago. 2010. Disponível em:

<http://www.scielo.br/pdf/rlae/v18n4/pt_23>. Acesso em: 2 set. 2020.

MONTEIRO, J. C.; RODRIGUES, S. F.; PINHEIRTO, S. C. Comunicação, Educação e Tecnologias: reflexões interdisciplinares sobre o Kahoot. Trivium - Revista Eletrônica da Faculdade do Cetnro do Paraná, Pitanga: UCP, v. 6, n. 3, jul./dez. 2019.

MORAN, J. M. A educação que desejamos: novos desafios e como chegar lá.

Campinas: Papirus, 2007.

PITOMBEIRA, J. R. O Kahoot e o ensino de álgebra nos anos iniciais do ensino fundamental. 2020. 124f. Dissertação (Mestrado Profissional em Matemática) Universidade Federal de Alagoas, Maceió, 2020.

SANTOS, E. Pesquisa-formação na Cibercultura. Santo Tirso, Portugal: Whitebooks, 2014.

SERRES, M. Polegarzinha. Rio de Janeiro: Bertrand Brasil, 2013.

VERSUTI, A.; SILVA, D. A transmidiação como uma escrita de resistência. Revista Linha Mestra, São Paulo, n. 33, 2017. 